\title{
Trust makes this organisation unique
}

\section{Looking at the future of work through two human-centric organisations}

\author{
Sofi Kurki ${ }^{1}$ (D) $\cdot$ Markku Wilenius $^{1}$
}

Received: 31 July 2016 / Accepted: 7 November 2016/Published online: 9 December 2016

(C) The Author(s) 2016. This article is published with open access at Springerlink.com

\begin{abstract}
Modes of organising have an indirect relationship with the new key technologies as enablers of new forms of organisation. The effect is two-fold: first the emergent technologies bring more efficiency to traditional organising, while at the same time inspiring ideas about new ways to approach the everyday life of organisations. Secondly, the metaphors and models based on new technology are applied to building new forms of organisational interaction. In this article we argue that the metaphors that are currently beginning to affect organisations on a larger scale are derived from networked communication technology. Pentti Malaska, a Finnish Futures Researcher, based his theory of societal change on the idea that societal forms build upon one another as a succession of needs that remain unfulfilled by the previous stage of development. He presents the next stage as society of intangible needs, where the focus of human activities will move to interaction between people. We present the results of an investigation of two case studies: Finnish IT-consultancy firm Reaktor, and Buurtzorg, a Dutch home care organisation. They both have adopted networked practices that question the traditional command and control management structures, and replace them with self-organisation, social control, and trust. In our research we are focusing especially on how technology affects the way these organisations approach their employees and clients. These empirical findings are reflected against the theory of society of intangible needs for contextualising the results, and drawing out their potential implications for the organisations and working life in the coming decades.
\end{abstract}

Sofi Kurki

sofi.kurki@utu.fi

1 Finland Futures Research Centre, University of Turku, Korkeavuorenkatu 25 a 2, 00130 Helsinki, Finland
Keywords Future of work · Human-centric organisation . Non-hierarchical organisation · Teal organisation . Ethnographic research $\cdot$ Society of intangible needs

\section{Introduction}

The question of how technology affects society is one of the central issues not only in Futures Studies, but in social sciences in general. The dynamics of how an emergent technology or a technological cluster affects societal practices are far from being clearly understood, and yet they can be argued to be at the very core of any forward-looking activity involving social aspects. In this article we aim at understanding the effect of technological change through micro-level practices in the working life.

The current projections for the future of working life assume a rapid development of AI, allowing replacement of not only physical rote tasks, but increasingly jobs that thus far have been considered as "white collar" expert work [1]. This projected shift has already been labelled as the third industrial revolution [2] and it has evoked provocatively bold statements from its scholars, such as the key claim that "Digital technologies are doing for human brainpower what the steam engine and related technologies did for human muscle power during the Industrial Revolution." [3].

The first and second industrial revolution together are generally considered to have led to the development of the modern organisation [4] that took automorphic inspiration from the very machines that were at the core of modern industrial production [5]. A similar transfer from a technological model to human practices has been visible also since the formation of the Internet, as the strengthening and popularisation of various kinds of network models for understanding human communication and collaboration [6]. Yet, the question of the full 
effects of the projected third industrial revolution on the level of working practices is still largely unanswered.

Attempts to understand the broad societal effects of multipurpose automation have mostly been based on historical analogies on the effects of the first and second industrial revolution, as well as projections of the ongoing societal trends into the future. These analyses suggest that the growth of economic disparity and hollowing out of the middle-classes in countries as different as United States, Germany, Sweden and Finland, has a relationship with technologies that on one hand shift investment from labour to machinery ${ }^{1}$, and on the other hand have an effect of diminishing demand of the midto low-level skilled labour ${ }^{2}$. This development, if it were to unfold directly from the current trends, could then be assessed to mean significant loss of employment possibilities, and lead to a period of massive reorganisation at least within the industrialised societies, that predominantly rely on paid fulltime employment as the main mechanism for participation in the society [9]. However, the analysis on the effects of radical restructuring rarely venture out further than exploring other potential ways for ensuring basic subsistence mechanisms in such a situation, such as models of basic income [10].

In this article we wish to point out that there may, however, be other societal possibilities and effects that are linked with the technological transformation, but that are not yet visible through quantitative, indicator based study. Instead, we offer two organisations as cases of such effects.

To make our argument, we need to take a broader view to the future of work as part of societal development: The case studies are reflected against a theoretical framework that combines the macroeconomic perspective of the long-wave approaches with a theory proposed by Pentti Malaska, which draws attention to the intentionality of social dynamics in change processes. Malaska connected technological and scientific advances to increasing complexity and social progress. In his theory, digital technologies and a high level of complexity, combined with advances in society's ability to fulfil Maslowian needs, will in the next phase of development result in a society of intangible needs [11]. In this article we reflect on the consequences of such a shift for the future of organisations. The practices of our two case organisations: an ITconsulting firm Reaktor, and a home care organisation Buurtzorg, are reflected against this broader background of societal change. The cases are regarded as future signs [12],

\footnotetext{
${ }^{1}$ Although there are scholars who decouple this development, ongoing already for several decades, from the technological development and rather view it as a consequence of the combined effects of political decisions and financial incentives [7]

${ }^{2}$ This argument needs to be balanced out by noting that it is difficult to assess the exact impact of technology to the issue, to which other contributors include the effects of globalisation, economic growth, access to education, etc. Yet, the effects of automatisation, if the technology advances as projected, are likely to increase in the future and potentially surpass the outsourcing and other effects experienced so far [8].
}

a concept that in Futures Studies denotes phenomena that is at odds with mainstream practices, but can be used to illustrate possible futures.

\section{How technology affects social change}

Theories addressing macro-level societal change often approach the issue through a combination of economic and technological driving forces [13]. A major intellectual lineage runs through Nikolai Kondratieff's observation that capitalist economies tend to develop in waves of rising and declining prices of basic commodities [14], to Joseph Schumpeter's work connecting such fluctuations to (technological) innovation $[15,16]$. This work has later been continued by Christopher Freeman (e.g. [17]), Carlota Perez (e.g. [18, 19]), and W. Brian Arthur [20], who have drawn attention to the systemic nature of the phenomenon, and pointed out that the only way to understand the issue is through looking at it as a socioeconomic system with various feedback loops. Throughout this line of thinking it is implicitly assumed that technology as an individual force of development evolves through different phases in a process not completely unlike that of biological evolution. As in the case of biological evolution, the direction of such evolutionary processes remains open.

As a reaction against this seemingly haphazard nature of societal direction, we find a second, more recent approach, that we here call "guided evolution" view to societal change. It is most evident in the transition management approach to innovation [e.g. 21] and present also in other frameworks under transition studies [22]. There, a much more significant role is given to humans as conscious agents shaping and directing technology development towards sustainability transitions. The key idea is that technology development paths and patterns can be affected by creating special, protected areas where novelties can develop without being exposed to the harsh forces of the marketplace before being fully matured.

Pentti Malaska's dynamic model of transformation sees societal development as a learning process resulting in social progress as a function of time. For Malaska,

"the essential difference between natural systems (chemical, biological, ecological systems) and human systems (societies, enterprises, etc.) is that in the latter, the impulses causing primary fluctuations are initiated not only by chance but by man himself and can be made by him consciously." [11]

Thus, while acknowledging the role of chance in the development of human systems, conscious control through intentional action is the key differentiating factor between human and natural systems. 
One way of looking at Malaska's theory is to see it as an all-encompassing theory, under which both Kondratieff's cycles and the transitions - school fall as manifestations of human intentionality in affecting the direction of the future. This interpretation is supported at least by the long-wave theorists' tendency to emphasize the long wave mechanism as contingent on the decisions and choices made by various actors in the socioeconomic system [23].

By establishing a link between the intentions of human actors and the development of socio-technical systems, and, moreover, by postulating a general direction for it, Malaska takes on a major challenge of explaining the dynamics of this relationship. In the following chapter we will give a more comprehensive account of this dynamic.

\section{The society of intangible needs}

A common point of departure for all the theories presented above is assuming an alternation between steady states of development, and transformational periods, when the system re-organises itself due to pressures stemming from the environment, often from technological development. For Malaska, stages of qualitatively different modes of production, organising, economic systems, but also different worldviews and aspirations arise out of the needs created by the previous technological phase. In Malaska's theory, the fluctuations between different developmental phases follow a pattern of extensive growth ("more out of more") leading to intensive growth ("more out of less") and then on to a qualitatively different focus in the following cycle, catalysed by a technology that enables the previous intensive growth phase. Instead of a steady wave-like fluctuation, the phases of societal development connect with the constant desire of humans to satisfy their existential needs. Societal eras are then defined both by the available technologies and by the extent to which the technology can help in fulfilling these needs ${ }^{3}$. Thus, the first of Malaska's societal phases, which is commonly referred to as the agricultural phase, is in Malaska's terms the society of basic needs, where technologies evolved for a more efficient and reliable production of food and shelter, the basic level of Maslowian hierarchy of psychological needs. The emergence of a new phase of development was then catalysed by a "germ" that represents a qualitatively different way of operating. The technology that functions as the germ first emerges as a way to enhance the production within the dominant sector. In the agricultural phase the germ to introduce the next phase of development were embryonic industrial techniques of

\footnotetext{
${ }^{3}$ Here Malaska refers to von Wright's [24] definition of a need as "something a being is not well without".
}

producing agriculture, which then evolved into the industrial age that would add to the satisfaction of basic needs another layer, that of the production of material goods. Following the same logic, information production and processing are the germs that first strengthen, but eventually will transform industrial production into the next phase, which Malaska envisions as the society of intangible needs. Like the shift from agrarian to industrial society led to the industrialisation of agriculture, the new focus is likely to alter industries towards serving the new focus [11].

The drivers for change from the society of material needs to the society of intangible needs come on one hand from the saturation of the need for material goods for producing wellbeing. This driver is supported by evidence of increasing environmental stress caused by industrial production and unmet spiritual needs of people that together result in wide-spread discontentment [25]. For Malaska, a shift to a new phase means a shift in the primary focus of activities, it does not mean abandoning the previous activities. As the technologies and processes for providing for the basic needs in the agricultural phase became unproblematic enough, the focus could shift to providing material goods to elevate the level of subsistence. The argument goes that the same is now happening to material needs in advanced industrial economies, and therefore a shift towards fulfilling needs that are more of a psychological nature is happening,

"Industry is by far the most effective means for the production of tangible products. It will also be like that in the future. However, what changes is the mechanical systems thinking that is converted to include human interaction. This is because human interaction and communication cannot be accomplished industrially and with tangibles only. And that is where we have the biggest gap in our advanced societies based on tangible needs." [26]

Based on a systematic analysis of the occupational structure in USA and Finland, Malaska argued that the proportion of tasks requiring human interaction skills had grown faster than the proportion of technical tasks. He saw this shift towards the service industries as indicative of the kind of changes automation would increasingly impose on human activities [27]. For Malaska the new needs whose fulfilment humans are freed to pursue by automation are primarily human-centric, and have to do with the relations between individuals, interaction, and information. Thus, the essence of work in the society of intangible needs would be related to solving issues that restrict the full exploitation of the communicational capabilities. These can relate to, for example, more efficient use of information for material resource utilization and recycling, and also to removing waste from organisational processes. 


\section{The evolution of organisational forms}

Malaska's theory gives an overall framework of change that touches upon all human enterprise. To root it in the organisational context, we turn next to Fredric Laloux' work on the evolution of organisational forms [28]. By describing the historical development through several adaptive stages, Laloux engages in an account of how the rise of complexity has pushed organisations towards assuming new operational modes.

According to Laloux, there have been four major perspectives in the history of human organising, with the fifth one as currently emerging. Though each model has been the dominant form in a particular historical setting, traces and representations of all of these five forms are still visible in the contemporary society [28].

The first paradigm was a tribal organisation, initiated around 15000 years ago. It was a move from atomized families to more stable organisations. Tribes were small, mobile and constantly engaged in territorial disputes and slave taking. Organisations were held together by undisputed authority of the leader, who needed to inspire fear among his/her own group and show no signs of weakness. Today, street gangs, mafia and mercenary armies represent the kinds of qualities Laloux assigns to tribal organisations.

Along with the need to create more stable conditions for human settlements to grow, the first agrarian societies, with a more complex structure in comparison with the hunter-gatherer tribal systems, formed an organisation that was set on stable rules. One of the key innovations of that phase was institutionalized religion, which was created along with the stratification of social order leading to formal hierarchies and replicable practices. The reign of this organisational form spanned from the first agrarian settlements to the Middle Ages. Representations of this organisation type have been preserved in the (Catholic) church, as well as in armies and hospitals.

The birth of modern societies along with the proliferation of the scientific method marked the emergence of the third type of organisation. In a world where people no longer referred to God or magical forces for their everyday decisions, the profit seeking, often innovation driven organisation gave structure and rationale to the everyday existence. Today this form is still the predominant form of organisation in most societies. Unlike the previous models, they are based on optimization, accountability and management by objectives, all ways to address the challenges of an increasingly complex environment brought about by global trade, and democratization of societies.

The fourth organisational model was born as a reaction against the self-interest and hierarchy centered paradigm of the previous phase. A strong internal cohesion, culture, as well as information and knowledge as the basic building blocks define this set of organisations. NGOs are examples of types of organisations working in this mode. Their number has risen sharply in the last years. ${ }^{4}$

Laloux postulates a currently ongoing transition, where a fifth type of organisational model is emerging. Three principles characterize this model:

1. Self-Management. Self-organised, team based model of organising creates order without hierarchies. The main argument for adopting this arrangement is based on the tendency of hierarchies to foster rigidity in high complexity environments. In practice, self-management means that the teams doing the actual work have autonomy in deciding how they actually go about their work. The networked model that such organisation is built after is a common feature of all complex systems (human brain, global economy etc.).

2. Wholeness. Authenticity in terms of not needing to differentiate between "home" and "work" identity is central in the ethos of self-managed organisations. This feature provides for an intensified feedback and evaluation system of the organisation, as "stupid questions", failures, and calls for assistance are not only tolerated, but used as a way for collective learning to occur. Wholeness thus refers to aiming for creating a sense of safeness within the organisation.

3. Evolutionary purpose. In traditional organisations the role of the leadership is to create a strategy and see to its implementation plan. The self-organising model forgoes strategy for an intent about where the organisation wants to go. The leaders task is to sense this natural tendency and support it. A metaphor for a self-managed organisation is a living organism, and similarly, organisational practices are attuned to sense changes in the environment. Instead of trying to predict the future, the aim is to to maintain a connection to the surrounding reality, and adjust accordingly, with preserving the intent of the organisation.

\section{Complexity, control and trust}

In both Malaska's and Laloux' thinking the increasing complexity is a main driver for new forms of societal or social organising. Complexity increases as a result of increased communication, and the past decades have seen the vast expansion in the amount of potential nodes to be reached within a global, technology enabled network [29].

The practical implications of increased complexity for the modes of organising in societies and organisations have to do with a fact that the operational environment has become

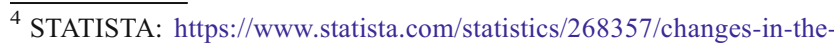
number-of-ngos-worldwide-since-1948/
} 
increasingly difficult to manage through old control and decision-making structures. In dynamic environments, hierarchical structures present several obstacles to flow of relevant information in the organisation

1) only codified information is transferable [30]

2) governance layers filter and modify information, presenting a problem for noting and acting on uncertain information, like weak signals [31]

3) in a hierarchical decision-making structure, the complexity of the decision-making entity cannot match the complexity level of the environment [32]

Decentralization of decision-making authority to the level of the individual eliminates the need for codifying and filtering the information. It also responds to the third challenge by increasing the ability of the decision-making entity to take on the complexity of the environment by broadening the decision-maker base.

Complexity also increases the risk and uncertainty involved in decision-making, which are inherently tied with trust, as is evident in the following, widely used definition for trust in relation to organisational behaviour: (Trust means) "the willingness of a party to be vulnerable to the actions of another party based on the expectation that the other will perform a particular action important to the trustor, irrespective of the ability to monitor or control that other party" [33].

Research on trust in organisations has assigned it an important role in efficiency and effectiveness of communication [34], as well as in organisational collaboration and cooperation [33] and innovativeness [35], all of which are important dimensions in self-managed working model.

\section{Methods and data}

The society for intangible needs is not presented as a prediction, but rather as a conceptual framework (e.g. [11]). Yet, it does provide enough concreteness to be utilized for assessing current phenomena in a futures oriented framework. In order to do this, we need to clarify the basic concepts that Malaska uses to describe the shift:

Key concepts that appear in depictions of the society of intangible needs are communication and technology, social vs. technical skills, organisational units, and progress, development and growth. In the next section each of these is elaborated based on Malaska's writings on the topic.

Communication and technology The concepts of communication and technology are intertwined in Malaska's depiction of the society of intangible needs. Digital information technology enables the fulfilment of fundamental psychological needs related to communication and interaction, and technology also acts as a model and backbone for a society that enables focusing on human qualities such as the communicative capability.

Progress and development mean positive development based ultimately on the mental and spiritual growth of human beings, while the concept of growth itself is approached in a more ambivalent fashion:

"The quantitative growth has changed those that have been subject to growth -economies and their interaction - to the extent that the further growth has become ever more difficult to achieve in the accustomed ways, fields and regions of activity. Moreover, there is no longer such a strong belief, as there was earlier, in the ever-increasing expansion, even when there seems to be no limits to it." [26]

Organisational units Malaska assumed that in the next societal phase, the interaction between human beings will take on a much more prominent role. This would mean for instance that family-like formations, not based solely on blood ties but on much larger entities, would start forming. These familylike organisations could also resume the traditional role of production units, lost in the society of material needs and the core family concept [36].

Social vs. technical skills Based on a statistical survey of how the occupational structure had evolved in USA and in Finland, a conclusion was drawn that technologically more advanced societies tend to produce work that requires more social skills - against a common intuition that technical skills would prevail in such conditions. In the 1980s, the extent of the analysis, Finland was found lagging behind USA in having a more technically oriented workforce [27].

As the society of intangible needs is in effect a society where the focus is on interrelations between individuals and groups, in our empirical data we have systematically focused on the way the case organisations approach their employees and clients. We have thematically coded the material by using the prevalent categories of Malaska's theory (communication and technology, social vs. technical skills, organisational units, and progress, development and growth). We also systematically look for instances that suggest departures from Malaska's view of the society for intangible needs, thus allowing for alternative interpretations.

In this article we base our investigation on two case studies in two different fields (IT consultancy company Reaktor, and a home care foundation Buurtzorg, both relatively young organisations: 16 and 10 years respectively) that according to several metrics have been identified as leaders in their own 
respective sectors ${ }^{5}$. Their practices are presented, compared with one another, and then reflected against a theory of society of intangible needs proposed by Pentti Malaska [10]. Our primary case is a Finnish IT-consultancy organisation Reaktor, where our data consists of three months of nonparticipatory ethnographic research from March 2015 to June 2015, supported by six thematic interviews with members of the organisation made during the same timeframe. The secondary data comes from Buurtzorg, a Dutch home care organisation, where eight employees and founders were interviewed in either individual or pairwise thematic interviews during one week in May 2016. The Buurtzorg data is complemented by an exhaustive literature review of extant research on the organisation $[28,37]$. We use the two case set-up to compare potential similarities across different fields, but also to offer examples of alternative practices within a general human-centric framework. While the novel forms of organising have gained foothold especially in IT, in literature cases of self-managed organisations have been described in over 20 different fields of business [28], ranging from schools to industrial engineering, and energy systems operators. In the writing of our case descriptions, our aim has thus been to draw attention to the generalizable features, that serve as illustrations of how the key functions in organisations: planning, organising, leading and controlling [38] can be arranged without resorting to hierarchical practices.

\section{Case descriptions}

\section{Working at Reaktor brings out the best in you}

"Being self-organised simply means that our teams have the freedom to choose how they work, observing any conditions set by the client or the project itself. To reach and enact a decision, the team doesn't need to consult our executive group or anyone else from the head office. In fact, the main function of the head office is to facilitate the work of our teams by means of financial management, sales, recruitment, and administrative support...Indeed, one way to think of Reaktor is to consider a group of networks, or links between people without an imposed hierarchy. The more links between people and the stronger these links are, the stronger the network becomes."

\footnotetext{
${ }^{5}$ Reaktor and Buurtzorg have both won awards as best working places in their own countries, Reaktor also in Europe. Both have grown extremely fast, Reaktor from 10 employees to 360 since its formation in the year 2000, and Buurtzorg from a handful to almost 10000 workers since 2006.

${ }^{6}$ Quote from Reaktor's blog: http://reaktor.com/blog/how-reaktor-grewwithout-hierarchy.
}

Reaktor was founded in the year 2000, with 10 founding members. The guiding aim of the founders was to form a company they themselves would like to work in: focusing on doing good work on interesting projects, and minimizing unnecessary office bureaucracy. From its beginnings with just a handful of employees, Reaktor has grown to a company that has 360 employees, and 43 million euros in turnover in 2015. The size has over doubled in the last three years from under 150 to its current size. Originally Reaktor's focus was solely on technology and it sought after only extremely experienced developers to its teams. However, it has since broadened its functions to better respond to market needs, and now self-describes itself as a creative technology firm that combines "code, user-experience design, visual design, concept design, analytics, content planning and growth hacking”. Agile working methods and lean philosophy form the core of Reaktor-practices. Many employees have scrum-master certificates, and in the daily practice the agile principles are extensively applied.

The Agile method provides a blueprint for understanding structure and practices at Reaktor ${ }^{7}$, but the culture is not reducible to this philosophy alone. In our study we have considered the Agile methodology as part of the culture, and thus not coded it separately from other aspects of how Reaktor operates. In the life of a Reaktor team, the Agile method is present though rituals, such as

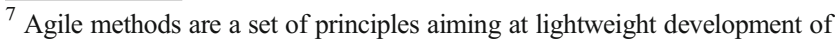
software. Key features in any Agile methodology are adaptive planning, evolutionary development, early delivery, and continuous improvement, as well as a rapid and flexible response to change. Agile methods were developed as a counterforce against the so-called waterfall-methods, which were experienced as too regulated and micro-managed. Agile methods were summarized in Manifesto for Agile Software Development by 17 software developers, who convened together to discuss lightweight methodology. It states the following as elements of Agile:

1. Customer satisfaction by early and continuous delivery of valuable software

2. Welcome changing requirements, even in late development

3. Working software is delivered frequently (weeks rather than months)

4. Close, daily cooperation between business people and developers

5. Projects are built around motivated individuals, who should be trusted

6. Face-to-face conversation is the best form of communication (colocation)

7. Working software is the principal measure of progress

8. Sustainable development, able to maintain a constant pace

9. Continuous attention to technical excellence and good design

10. Simplicity, the art of maximizing the amount of work not done, is essential

11. Best architectures, requirements, and designs emerge from selforganising teams

12. Regularly, the team reflects on how to become more effective, and adjusts accordingly.
}

see: http://agilemanifesto.org/. 
the daily, which means that the team gathers together to start the morning by examining the current state of the project. Acute tasks are presented on the wall with postit pads, along with indicators of who of the teammembers is responsible for/working on what. The benefits of the procedure include keeping visible track of the progress as well as helping to build next steps as a team, visualizing the project to the client (whose representative often participates in the daily), helping to prioritize tasks, and allowing each team member to focus on one thing at the time. In the daily, everyone participates in planning and reflection of how things could be done even better, and what needs to be taken into account while proceeding. At the end of the week teams have a "Retro" session, in which the team reflects upon the past week on a more general level, as well as processing issues related to team dynamics, and practical matters. Teams also communicate their work to a larger client audience as forms of "Demo sessions" and occasionally with a more formal meeting where members of the team, client, and Reaktor head-quarters representatives discuss on the project on a more strategic level.

At Reaktor, power and responsibility about a project reside in the team doing the work. The teams work autonomously of the headquarters, but get support if needed. HQ also acts as a community platform, where informal face-to-face interaction with other Reaktor employees takes place (this is also actively promoted, and people are encouraged to get to know each other). The teams are relatively fluid in terms of membership: new members are appointed and old members shift teams during the project. Members of teams do not have roles (team leaders etc.). There are differences in professional expertise, but all participate as equals in team dynamics. The project work is based on communication: consulting the colleagues both in the team and through virtual channels (support and expertise from colleagues in other teams is readily available and volunteered). Decisions about the project are done by individuals in the teams. As a basic rule, one can make a decision after consulting colleagues. One does not have to take the advice of the colleagues, but it is mandatory to ask for feedback before making a decision. The whole team needs to be able to stand behind the decisions made in the team (this does not however mean consensus needs to be reached about everything).

The teams work directly with the customer. People, whose opinion is needed are contacted directly, not via their superiors. Direct communication is preferred over meetings. Projects typically produce little written documentation but there are extensive information sharing resources, and the teams actively seek out feedback from the clients, and from each other.

Conflicts and issues are mediated primarily within the team by the team members. Reaktor has at its disposal external facilitators who can be used to help, and Reaktor employees have also been given facilitator training.

Reaktor teams work in their clients' premises. At the outset of each project they claim a space for their work by bringing in their own tools, and typically "Reaktorians" furnish their working space also with coffee machines, refrigerators (filled with beverages and snacks) and other equipment. On occasion they have asked walls to be removed to enable fitting people in to the same room. Screens for viewing on-line data are mounted on the walls, and pull-up bars for inter-team competitions installed to doorways. Clients are offered access to all Reaktor hospitalities.

The homely feeling created in the working spaces is highlighted by the informal dress code of the Reaktorians. They often wear company t-shirts, and some go barefooted. The teams refresh during the working day with coffee and tea breaks. One of the Reaktor principles is that longer than eight hour working days are not encouraged, due to the risk of burnouts from too intensive focus on work, but on the other hand the realisation of the importance of private life.

Reaktorians form a tight community but one that extends beyond the official borders of the company. In recruitment, having "passionate" hobbies and active lifestyle that go beyond the professional identity are highly valued qualities. Reaktor also take various initiatives to reach out to the families of the workers, by for instance arranging a coding school for children, where Reaktorians teach on a volunteer basis coding skills.

Team members often refer to what something feels like, and this is a valid argument in discussions:,"I hope you are not feeling bad after this discussion. I am sorry that I got so anxious about this thing. We should take everyone into account as human beings!" In reflections the teams also try to understand the clients from the perspective of their potential emotions, "I think that the client is worried about ...." Team members are clearly aware of this dimension in the team dynamics, "We try to take others' feelings into account or at least identify that such exist, everyone needs to feel comfortable as part of the team!" and they also consciously use the emotional dimension as part of their communications with the clients, "Even in the client interaction, we try to find out why they said that, we need to understand what they are worried about...what it really means, not just do what they ask."

Clients are part of the daily functioning of the teams. Close interaction with the client is a central part of the Agile philosophy, and Reaktor's teams working at client's premises has evolved into a general practice. Although the need for such a practice with contemporary technology was in discussions sometimes questioned, and even if some teams spend a number of days in a week also in their own office, working at the clients' space is in general accepted as a given in project work.

Reaktor has a policy of always having at least two Reaktorians in a project to help them maintain the Reaktor 
way in doing the work. Reaktor aims at having a set-up where the team members mix freely with the client organisation's representatives. If possible, they want to have all the people who are active in the project sit in the same room, to be as available and within the communicational sphere as much as possible. Even if the Reaktor team had been given their own room for practical reasons, during our observation, clients came and went through the team space naturally, without raising much attention.

The client's comments about Reaktor's way of working were generally very positive and appreciative: describing it as a "Relaxing way of doing things" or "Refreshing with new ways of doing things". Several commented about how their own organisation had grown more dynamic with the example of having Reaktorians in their amidst, and there have been requests for Reaktor to teach their working method to more traditional organisations. Yet, an intimate collaboration often with two quite different set of assumptions about organisational structure, client-provider relations, and the way projects generally proceed are fertile ground for culture clashes. These are usually related to the way in which Reaktorians approach traditional organisational cultures unchallenged assumptions related to hierarchical decision-making, conventions such as scheduling meetings for any decision, and the need to document and plan projects, instead of relying on instant feedback and functional sub-parts of the project.

The employees at Reaktor see a direct correlation with the success of the firm and the success of all the employees: through bonuses for everyone based on profit-making, but also on a more universal level. Ownership was decided to be offered to all the employees in the beginning of 2016 (previously the company was owned by long-time employees and founders). This was generally received positively, as adding more transparency to even this part of the organisation (Table 1).

Buurtzorg (meaning neighbourhood care in English) has its roots in the history of the Netherlands' home care system. Up until the 1980s the home care was based on a system relying on district nurses, who worked independently and had responsibility over home care within their area. However, like in other western countries, this system was then redesigned in the hope of cutting costs by more efficiency gained by re-distributing the care to business organisations. They in turn divided the care to different procedures of varying levels of competency demands by the nurses. Jos de Blok, the founder of Buurtzorg, is a nurse and has also a degree in business administration. In the beginning of his career he worked as a district nurse, but later moved on to work as an innovation director at a large health-care firm. It was there where he realised the need for an organisation like Buurtzorg that would bring the primary process of nursing back to the centre of nursing organisations, as he noted how "management easily becomes the purpose of its own". He wanted to break from that two-store house type of normal organisation, where managers do not understand the type of issues nurses are actually concerned with. De Blok had the insight that the organisation should only have a role as a supporting function that would enable the best possible care for the client. Buurtzorg was founded in 2006 by a core team consisting of de Blok, his partner Gonnie Kronenberg, who had a long experience from administrative functions in healthcare, and Ard Leferink, an IT-expert.

The aim of Buurtzorg from the beginning was to create an organisational model that could challenge and question the prevailing forms of healthcare. The aim was simply to show how the skills and experience of the nurses could be better utilized in the organising local health care. As one of the founders Jos de Blok observes now, "we wanted to change the discussion on healthcare. Defining healthcare as financial products was not the right thing to do. We said we should focus more on what kind of problems people meet in their life and how can you contribute and solve these problems". This meant, in essence, that all the care-taking should aim for helping the client to become more self-supporting, i.e. more independent human beings.

The idea of self-supporting systems is extended to the whole organisation. Buurtzorg is entirely organised around independent self-organising teams. They take care of their clients with the key aim of supporting their autonomy and fast recovery. The nurses try make use of all possible ways to reach this aim, including mobilising and involving the client's own social networks to take part in the care. Technology has been a central part of enabling this networked approach to work, and it was clear from the start that the types of tools Buurtzorg would need should be designed particularly for them. When developing the IT-system, the approach was to ask directly from the teams "what do you need for your daily work?" With this attitude, the whole organisation was developed: to serve the nursing teams to do their job as well and efficiently as possible and to allow nurses to think of their clients' best only, and not what their organisation was needing from them in terms of reporting or other bureaucratic practices. The idea to use the best possible information at every decision is visible in their recruitment process too. New people are always interviewed by the teams that they are supposed to work with. This ensures that both incoming employee as well as the team have a chance to do a down-to-earth compatibility check.

The operating model of Buurtzorg was originally incompatible with the general healthcare framework in the Netherlands: for instance, remunerating for singular procedures and not the overall results has not been favourable to Buurtzorg's systemic approach. Despite these difficulties, Buurtzorg has grown extremely rapidly, after ten years following its inception there are over 10000 nurses working for Buurtzorg, and it has been voted to be the best employer in Holland every year since 2011 (Table 2). 
Table 1 A summary of Reaktor observations [39]

\begin{tabular}{|c|c|c|c|}
\hline Company says & Teams say & Teams do & Client says \\
\hline Community & "Our team feels like a family". & $\begin{array}{l}\text { Collaborative decision-making: everyone's opinion } \\
\text { matters. }\end{array}$ & "Hi honeys!" \\
\hline Focus on doing & "We don't book meetings". & $\begin{array}{l}\text { Passive resistance to meetings practice, but seek to } \\
\text { solve the issue immediately so that the project } \\
\text { proceeds. }\end{array}$ & $\begin{array}{l}\text { Natural and } \\
\text { spontaneous } \\
\text { co-operation }\end{array}$ \\
\hline $\begin{array}{l}\text { Empowering the teams } \\
\text { in decision-making }\end{array}$ & $\begin{array}{l}\text { "We don't want any asshole bosses" "There are } \\
\text { no fixed roles", "The one who happens to be } \\
\text { around will communicate with the client" }\end{array}$ & $\begin{array}{l}\text { No corporate ladder to climb, team members are } \\
\text { treated equally. Challenging the team to better } \\
\text { performance with constant sparring and leading } \\
\text { collective self-control: asking e.g. How effective } \\
\text { do you think you were today? }\end{array}$ & $\begin{array}{l}\text { Need to justify own } \\
\text { opinions }\end{array}$ \\
\hline $\begin{array}{l}\text { Minimizing } \\
\text { bureaucracy }\end{array}$ & $\begin{array}{l}\text { "It's everyone's responsibility, you don't have } \\
\text { budgets at home either do you?" }\end{array}$ & $\begin{array}{l}\text { People have the power to act immediately according } \\
\text { to own judgement. They feel responsible. People } \\
\text { are free to focus on what is most important. }\end{array}$ & $\begin{array}{l}\text { At first confusing, } \\
\text { but effective } \\
\text { results }\end{array}$ \\
\hline Quality work & "No flaws, let's get it right from the beginning" & $\begin{array}{l}\text { Constant testing is essential, other person tests, team } \\
\text { pressure, coaching other team members }\end{array}$ & $\begin{array}{l}\text { When will things } \\
\text { be ready? }\end{array}$ \\
\hline $\begin{array}{l}\text { Solely high level } \\
\text { professionals }\end{array}$ & $\begin{array}{l}\text { "we just do it", "only competence matters, not a } \\
\text { degree" }\end{array}$ & $\begin{array}{l}\text { Learning by doing, team or extended team helps: "If } \\
\text { we don't have the knowledge, we find out together } \\
\text { how to do it" }\end{array}$ & How can we trust? \\
\hline $\begin{array}{l}\text { Constant questioning of } \\
\text { given models, even } \\
\text { own existing } \\
\text { practices }\end{array}$ & $\begin{array}{l}\text { "How could we do it even better?" "What could } \\
\text { go wrong?" } \\
\text { "How do you feel today?" }\end{array}$ & $\begin{array}{l}\text { They prioritise and focus on what is necessary and } \\
\text { timely. A lot of visualization: tags who does what } \\
\text { now, planning together before doing. }\end{array}$ & $\begin{array}{l}\text { Takes time but it is } \\
\text { important }\end{array}$ \\
\hline $\begin{array}{l}\text { Social fit of employees } \\
\text { a priority }\end{array}$ & $\begin{array}{l}\text { "We want to recruit active people with hobbies } \\
\text { and interests" "How could I improve myself } \\
\text { as a person or as an employee?" }\end{array}$ & $\begin{array}{l}\text { They want to recruit the kind of people they would } \\
\text { like to hang out on their freetime. They recruit new } \\
\text { team members themselves. They invite family } \\
\text { members to team gatherings. }\end{array}$ & $\begin{array}{l}\text { Participating in } \\
\text { team } \\
\text { competitions \& } \\
\text { common } \\
\text { hobbies }\end{array}$ \\
\hline 200 years focus & Fast fail & Teams focus on the task at hand. & $\begin{array}{l}\text { Too much focus on } \\
\text { instant tasks }\end{array}$ \\
\hline
\end{tabular}

Beyond Malaska's framework, it is noteworthy that both organisations recognise their uniqueness as successful organisational pioneers, and as such their role in shaping the societal perceptions of work. However, the way they react to this differ. For Buurtzorg, despite numerous inquiries, there is no interest in professionally consulting other organisations towards adopting self-organising principles (although advice is given freely, even to their direct competitors). Their coreidentity and primary process they want to pursue developing is nursing, and taking care of their clients. Anything that would distract from that is considered unnecessary. For Reaktor, consulting other organisations in self-organising has become one of the many business areas they operate in. This relates to their general ethos of seizing opportunities that reflect the interests of people within the organisation. Anything that motivates employees, interests clients, and proves profitable as business can be considered as potential area for activity. Coaching also responds to the need for a higher purpose that many Reaktorians seek from their work: acting as an inspiring example for other organisations is one way, providing good functional services that make things easier to use is another.
What unites the two organisations most is the value placed on the respect and trust given to individuals in both organisations. At Reaktor the success is based on trust among the Reaktorians throughout the organisation: There is a low threshold of contacting anyone in the organisation, and personal, informal relations among the workers act as facilitators to honest feedback and generous information sharing. At Buurtzorg, the following dialogue from an interview sums up the significance of trust in the organisation:

Interviewer: Maybe as a last question, what is it in your own words that makes Buurtzorg unique?

Buurtzorg nurse: The trust. The trust in your expertise, the trust in you as a person, the trust in your talents. When you trust, you do. (...) The trust I finance well, the trust in the decisions we make, the trust in how to treat the clients, the trust we're doing our jobs well. And also the trust in ourselves as a person. Trust in everything. The work I did before (...) there was never trust! I always had to explain why I did something, until how late, what I did. But that's not the question here. 
Table 2 Comparison of key aspects of the case studies

\begin{tabular}{|c|c|c|}
\hline Category & Reaktor & Buurtzorg \\
\hline $\begin{array}{l}\text { Communication } \\
\text { and } \\
\text { technology }\end{array}$ & $\begin{array}{l}\text { Technology is the product, but it is also a key feature enabling } \\
\text { efficient inter-personnel communications, keeping track on the } \\
\text { success of work, and practicing extra-curricular activities, while } \\
\text { also constituting a major part of the social purpose and identity } \\
\text { of the organisation. }\end{array}$ & $\begin{array}{l}\text { Communication technology helps in organising around the } \\
\text { primary process, the purpose. } \\
\text { Advanced, customised technology frees nurses from rote tasks, } \\
\text { allowing them to concentrate on the nursing and face-to-face } \\
\text { interaction with the clients. }\end{array}$ \\
\hline $\begin{array}{l}\text { Social vs. } \\
\quad \text { technical } \\
\text { skills }\end{array}$ & $\begin{array}{l}\text { Focus on recruiting a workforce with the best technical skills } \\
\text { available. However, a "culture check" is performed at the time } \\
\text { of recruitment, and is related to the aim of maintaining the } \\
\text { organisational culture. Reaktor requires its employees to have } \\
\text { social skills, and the lack of them can override technical } \\
\text { expertise. }\end{array}$ & $\begin{array}{l}\text { Buurtzorg hires technically qualified nurses. Yet, social skills and } \\
\text { a certain social inclination are key to being able to flourish in a } \\
\text { self-organised team. Many nurses have left the organisation } \\
\text { over the years over issues related to social skills. In average, } \\
\text { informants attest that it will take about a year to learn the social } \\
\text { skills needed at Buurtzorg. }\end{array}$ \\
\hline $\begin{array}{l}\text { Family / } \\
\quad \text { organisation- } \\
\text { al units }\end{array}$ & $\begin{array}{l}\text { Reaktor operates through self-organised teams but their members } \\
\text { can fluidly be changed within the organisation. Reaktorians as a } \\
\text { whole share a common culture which allows them to relate to } \\
\text { others, even though in a large organisation not everyone knows } \\
\text { one another. In teams, the atmosphere is informal and members } \\
\text { feel like they can be their true selves amongst colleagues. } \\
\text { Reaktor does not consider itself a family-like organisation, but } \\
\text { boundaries between the working life and private life are fluid. } \\
\text { There is however a clear emphasis, even a requirement to have } \\
\text { hobbies and life beyond Reaktor. The risk of burn outs, and } \\
\text { problems of too much dedication to work are recognised and a } \\
\text { healthy work-life balance is seen as a countermeasure to this. }\end{array}$ & $\begin{array}{l}\text { Buurtzorg operates through self-organised teams that are geo- } \\
\text { graphically defined. Teams stay together as long as they don't } \\
\text { exceed } 12 \text { members. After that, a general rule is that they } \\
\text { should split into two smaller teams. A team has power over all } \\
\text { the practical issues related to their teams functioning, and } \\
\text { members have strong commitment towards the team and the } \\
\text { team members. Buurtzorg has also organisation wide events } \\
\text { and communication, but usually members identify very } \\
\text { strongly with their own team and their clients. Clients are } \\
\text { promised that they will only have a small number of people } \\
\text { visiting their homes, so that a family-like relationship can de- } \\
\text { velop between the clients and the nurses. At Buurtzorg com- } \\
\text { mitment to the client overrides most personal life interests, and } \\
\text { work-life balance is a chronic issue: for instance taking a va- } \\
\text { cation is difficult to arrange, because the clients need constant } \\
\text { care by the people who have committed to taking care of them. }\end{array}$ \\
\hline $\begin{array}{l}\text { Progress, } \\
\text { development } \\
\text { and growth }\end{array}$ & $\begin{array}{l}\text { Reaktor has grown rapidly based on its good reputation as a } \\
\text { working place, and good quality work. Growth requires special } \\
\text { attention due to aims of maintaining the communal } \\
\text { organisational culture, but on the other hand is seen as an } \\
\text { enabler of progress through more interesting and challenging } \\
\text { projects. Reaktor's development directions evolve organically } \\
\text { through the interests and capabilities of its members. Reaktor } \\
\text { maintains a low threshold for trying out and testing new } \\
\text { opportunities and directions. Those that have potential are } \\
\text { continued and can develop to becoming key areas of activity. }\end{array}$ & $\begin{array}{l}\text { Buurtzorg has grown very fast as a result of its model being } \\
\text { attractive to nurses. Growth is not a goal as such, but it has } \\
\text { made it easier to deal with other social entities in the system. } \\
\text { Development and progress relate to the way Buurtzorg is able } \\
\text { to change the discourse on home care and elderly care on a } \\
\text { societal level. }\end{array}$ \\
\hline
\end{tabular}

\section{Discussion}

Malaska's theory on societal development builds on a schematic representation of history, but its main raison d'être is supporting futures oriented thinking about possibilities that the current technological development trends, and societal trends, can lead to. Malaska's theory of the emerging society of intangible needs, formulated as a plausible and desirable vision for a high-tech society aspiring to a sustainable existence, resonates interestingly well with our findings.

So far, Western industrial thought has evolved from an engineering base to a thinking dominated by economic rationale in recent decades. The currently dominating economic mind-set first succeeded in cost-savings, but it has since resulted in under-investment in most Western traditional industries, and is notorious for creating short-term solutions that have proven to be problematic on the long run. This is what is referred to as industrial logic in Malaska's theory. The development of technology challenges this logic, as it draws this mechanistic optimization to its natural limits by offering to rationalize everything that can be rationally optimized. Technology promises to replace by automation any rote task, meaning the kinds of jobs involving repetitive patterns. While the contemporary concern for the detrimental effects of such development for the well-being of the citizens living within our current structures is more than justified, the discussion easily becomes inherently myopic in failing to provide reasonable alternatives to the socially dystopic trajectory that we seem to be in.

In the organisations we have examined we can see traces of a new kind of logic, which is based on a more systemic understanding of success factors. In our cases, 
the mission and purpose dictate every other aspect in the organisational life. Our findings from Reaktor and Buurtzorg are in line with the general assumption that in the future organisations will seek to use technology for everything that it can be used for. However, context specific decision-making that requires judgment, interpreting subtle cues, creative problem solving, ethical consideration and above all human-to-human communication, will become key elements in work, as they already are in our cases. There is currently nothing that suggests these needs to disappear with the emergence of sophisticated automation. Thus, organisations are likely to evolve to make the most out of those human abilities. For people, this shift in focus, at least in the cases we observed, increases job satisfaction, and makes work an integral element in life. At the root of the self-organised model in our cases seems to be a change in the mind-set which allows empowered individuals within the organisations the authority to pursue work that they see as meaningful and important. Designing and implementing IT-solutions that really meet the needs of the people they will be serving, and providing quality care that supports the autonomy of the clients to lead a good life, are only two examples of needs in our current societies that today predominantly are not met. Many comparable, deeply human but currently neglected, sources of work will be available even after adding layers of technology to our societies.

Within the long-wave theory framework, our observations fit into the general pattern of organisational change following and accompanying societal level changes, as the system reorganises following the emergence of new economic drivers. These observations coincide well with some of the earlier studies on the relationship between the long socio-economic cycles and the changes and demands on organisational life. Indeed, using the Kondratieff wave theory as a larger framework to understand the various demands of leadership, and the change of preferred values, shows that the values on which people build their lives on have an ever stronger link to the engagement levels of people [40]. The emerging new model of organisational behaviour suggested by Laloux [28] fits well into this larger framework of societal change.

To return to Malaska's theory, our cases seem to reflect the fundamental tenets of the society of intangible needs. In the organisations we observed, we found two somewhat different models: While Buurtzorg is clientcentred to its core, in Reaktor we find an organisation formed around its community. For Buurzorg, everything exists to serve the clients well. This is a vocation based organisation where the primary motivation for its members is to be able to provide the best possible care for the patients / clients. At Reaktor, the organisation itself can be considered as a type of tribe ${ }^{8}$ that does trade with other organisations (clients) in order to sustain itself. However, both organisations revolve around communication as a central organising structure, and key to their continued success. Also noteworthy is that although both organisations rely heavily on the community of the colleagues, the individual and her own motivation and drive to pursue professional ambition are at the core of what makes the organisations function. [41]

In this study we have examined two organisations that have taken human-centric principles as a blueprint for creating their work environments. Even though they are a part of a small movement, their model of organising is still very much a fringe phenomenon, and as such they are presented here as future signals rather than a trend. Although much is still open about the contents of the next long wave, the success of both of these organisations, as can be observed from their performance record, is rather phenomenal in the market place. This, if nothing else proves that they have found something fundamentally interesting and working.

Acknowledgements We wish to thank Reaktor and Buurtzorg for their invaluable help and participation in this research.

Tekes, the Finnish Funding Agency for Innovation, funding for project Human Being and Value in the Sixth Wave (HUVA) is gratefully acknowledged. We also thank University of Turku Graduate School (UTUGS) for enabling important background work for this research.

Open Access This article is distributed under the terms of the Creative Commons Attribution 4.0 International License (http:// creativecommons.org/licenses/by/4.0/), which permits unrestricted use, distribution, and reproduction in any medium, provided you give appropriate credit to the original author(s) and the source, provide a link to the Creative Commons license, and indicate if changes were made.

\section{References}

1. Frey CB, Osborne MA (2013) The Future of Employment: How Susceptible are Jobs to Computerisation? OMS Working Papers. http://www.futuretech.ox.ac.uk/sites/futuretech.ox.ac.uk/files/The Future_of_Employment_OMS_Working_Paper_0.pdf. Accessed 26 Oct 2016

2. Rifkin J (2011) The Third Industrial Revolution: how lateral power is transforming energy, the economy, and the world. St. Martin's Press, New York

3. Bernstein A, Raman A (2015) The Great Decoupling: An Interview with Erik Brynjolfsson and Andrew McAfee. Harvard Business Review. https://hbr.org/2015/06/the-great-decoupling. Accessed 26 Oct 2016

4. Starbuck WH (2013) James Gardner March: founder of organisation theory, decision theorist, and advocate of sensible foolishness. Eur Manag J 31(1):88-92

5. Morgan G (2006) Images of Organisation. Sage Publications, Thousand Oaks

\footnotetext{
${ }^{8}$ The tribal aspects of Reaktor's organisation are discussed in [41]
} 
6. Eriksson K (ed) (2015) Verkostot yhteiskuntatutkimuksessa (Networks in societal research). Gaudeamus, Helsinki

7. Jacobs M, Mazzucato M (2016) Rethinking Capitalism: an introduction. In: Jacobs M, Mazzucato M (eds) Rethinking Capitalism. Economics and policy for sustainable and inclusive growth. WileyBlackwell, Chichester, pp 1-27

8. Rotman D (2015) Who Will Own the Robots? MIT Technology Review. https://www.technologyreview.com/s/538401/who-willown-the-robots/ Accessed 26 Oct 2016

9. Arthur WB (2011) The Second Economy. McKinsey Quarterly. http://www.mckinsey.com/business-functions/strategy-andcorporate-finance/our-insights/the-second-economy. Accessed 31 July 2016

10. Kangas O, Pulkka V (eds) (2016) Ideasta kokeiluun? Esiselvitys perustulokokeilun toteuttamisvaihtoehdoista (From idea to experiment - Preliminary report on a universal basic income). Publications of the Government's analysis, assessment and research activities 13(2016). http://tietokayttoon.fi/documents/10616/2009122/13 Ideasta+kokeiluun.pdf/3c042238-163b-48a1-99cf-94dca35b4917 ?version=1.0 Accessed 26 Oct 2016

11. Malaska P (1999) A Conceptual Framework for the Autopoietic Transformation of Societies. Turku School of Economics and Business Administration. FFRC FUTUpublic ation 5(99). https:// w w w u t . fi/fi/yksikot/ffrc/tutkimus/hankearkisto/Documents/futu_5_99. pdf . Accessed 31 July 2016

12. Hiltunen E (2008) The future sign and its three dimensions. Futures 40(3):247-260

13. Wilenius M, Casti J (2015) The Sixth K-wave and the Shocks that May Upend It. Technol Forecasting Soc 94:335-349

14. Kondratieff N (1928/1984) 'The Long Wave Cycle' and 'The Theses of N.D. Kondratieff's Paper: Long Cycles in Economic Conditions' in The Long Wave Cycle, New York: Richardson \& Snyder, translated by Guy Daniels, p. 2599 and 101 5, 137 8. In Louçã, F. \& Reijnders, J. (eds.) The Foundations of Long Wave Theory. Models and Methodology. Volume I. Edward Elgar, Cheltenham

15. Schumpeter JA (1942) Capitalism, socialism and democracy. Harper, New York

16. Schumpeter JA (1939) Time series and their normal. In: Business Cycles: A Theoretical, Historical and Statistical Analysis of the Capitalist Process. McGraw-Hill Book Company, New York, pp 139-219, 1051

17. Freeman C (1993) Technical change and future trends in the world economy. Futures 25(6):621-635

18. Perez C (1983) Structural change and the assimilation of new technologies in the economic and social system. Futures 15(4):357375. doi:10.1016/0016-3287(83)90050-2

19. Perez C (1985) Towards a Comprehensive Theory of Long Waves. In: Bianchi et al (eds) Long Waves, Depression and Innovation, Proceedings of Sienna Conference

20. Arthur WB (2009) The nature of technology: what it is and how it evolves. Simon \& Schuster, New York
21. Kemp R, Loorbach D (2006) Transition management. A reflexive governance approach. In: Voß JP et al (eds) Reflexive governance for sustainable development. Edward Elgar, Cheltenham, pp 103130

22. Markard J, Raven R, Truffer B (2012) Sustainability transitions: an emerging field of research and its prospects. Res Policy 41(6):955967

23. Freeman C, Louçã $F$ (2002) As time goes by: from the industrial revolutions to the information revolution. Oxford University Press, Oxford

24. von Wright GH (1984) Tarpeesta (On human Need). Ajatus 41:2538

25. Kurki S, Wilenius M (2015) Organisations and the Sixth Wave: Are ethics transforming our economies in the coming decades? Futures $71: 146-158$

26. Malaska P (1983) Tulevaisuuspoliittinen hahmotelma (Framework for the politics of the future). Pellervon Taloudellinen tutkimuslaito

27. Malaska P (1998) Sociocybernetic transients of work in the lateindustrial period. USA and Finland as the empirical cases. SA XIV World Congress of Sociology, Montréal

28. Laloux F (2014) Reinventing organisations. A guide to creating organisations. Nelson Parker, Brussels

29. Castells M (2001) The Internet galaxy: reflections on the Internet, business, and society. Oxford University Press, Oxford

30. Powell TH, Ambrosini V (2012) A pluralistic approach to knowledge management practices: evidence from consultancy companies. Long Range Plan 45(2-3):209-226. doi:10.1016/j.lrp.2012.02.005

31. Ansoff IH (1984) Implanting strategic management. Prentice/ Hall International, New Jersey

32. Ashby WR (1956) An introduction to cybernetics. Chapman and Hall, London

33. Mayer RC, Davis JH, Schoorman DF (1995) An integrative model of organizational trust. Acad Manag Rev 20(3):709-734

34. Blomqvist K (2002) Partnering in the dynamic environment: The role of trust in asymmetric technology partnership formation. Dissertation, Lappeenranta University of Technology

35. Ellonen R, Blomqvist K, Puumalainen K (2008) The role of trust in organisational innovativeness. Eur J Innovat Manag 11(2):160-181

36. Malaska P (1999) A futures research outline of a post-modern idea of progress. Futures 33(3-4):225-243

37. Nandram S (2015) Organisational Innovation by Integrating Simplification: Learning from Buurtzorg Nederland, Springer International Publishing. Cham, Switzerland

38. Griffin R (2012) Fundamentals of Management. South-Western Cengage Learning, Mason

39. Pura M, Kurki S, Meinander M (2015) Team-to-team Relationship Dynamics: The tribal team as the success factor of future organisations. In: The Proceedings of the 23rd ICRM, Helsinki

40. Kurki S, Pura M, Wilenius M (2016) RE-acting the future. New Ways to Work: the case of Reaktor. Interim report for the HUVAproject. FFRC, Turku

41. Wilenius M (2014) Leadership in the Sixth Wave. Excursions into the new paradigm of the Kondratieff cycle 2010-2050. Eur J Futures Res 2:36. doi:10.1007/s40309-014-0036-7 